PRODUCTION

ENGINEERING ARCHIVES
2014, Vol. 4, No. 3, pp 7-10

ISSN 2353-5156 (print version)

ISSN (online version)

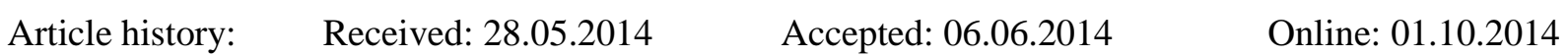

\title{
Lean tool used in the automotive industry
}

\author{
Manuela Ingaldi ${ }^{1}$, Marta Jagusiak-Kocik ${ }^{2}$ \\ ${ }^{1}$ Czestochowa University of Technology, Faculty of Management, Institute of Production Engineering, Al. Armii Krajowej 19b, 42-200 \\ Częstochowa, Poland, +48343250399, manuela@gazeta.pl \\ ${ }^{2}$ Czestochowa University of Technology, Faculty of Management, Institute of Production Engineering, Al. Armii Krajowej 19b, 42-200 \\ Częstochowa, Poland, +48343250399, m.jagusiak-kocik@ o2.pl
}

\begin{abstract}
In the paper basic concepts of Lean Manufacturing were presented. A company specializing in the development of vehicle dynamics, driver assistance systems, brake systems, seat belt sand electronics technology was characterized. The company is engaged in designing and manufacturing world-class products for the automotive market. The Lean tools used in the production hall, such as Yamazumi chart, machine motion analysis, MTM method and timing, were presented.
\end{abstract}

Key words - Lean Manufacturing, seat belts, timing, Yamazumi chart, MTM method, machine motion analysis

\section{Introduction}

Lean, according to J. Womack and D.T. Jones, is: "the removal of all unnecessary time, actions and causes of errors from raw materials to finished product, from order to delivery, and from idea to implementation" (WOMACK J.P., JONES D.T. 2001). Lean Manufacturing (LM) is a concept that has been developed in major part by Japanese automakers. Then it was implemented in a number of Japanese, American and European companies. LM is a philosophy of management, involving the continuous elimination of waste, defined as all activities, investments and processes which do not add value to the product or service from the customer point of view.

The essence of LM is constantly increasing labour productivity, in order to enable the company to compete successfully in the market (SYGUT P 2013; SZKLARZYK P. 2014).

It is achieved not through a reduction in employment or increasing workload, but thanks to the com- mitment of all employees in the process of improving the system.

\section{Characteristics of the research object}

The object of the research is a company with over 100 years of experience in the automotive industry. The company is a global leader in automotive safety. It occupies a prominent place in the development of vehicle dynamics, driver assistance systems, brake systems, seat belt technology and electronics. It is engaged in designing and manufacturing world-class products for the automotive market.

In Poland, there are six modern plants in four different locations. The analyzed plant is a manufacturer of seat belts, seat belt buckles, height controls and airbags and airbag modules. Among the various elements of safety seat belts there are, for example, socalled sewn zippers mounted in the rear seats of cars which are complete with hip belt locks fitted to the 
front seats, including the front with hook locks, and locks with a stiff pyrotechnic charge. Three-point belts are also produced.

The research object of study is one of the largest factories of seat belts in Europe. The seat belts are different from each other only in the kind of retractor which are equipped.

\section{Characteristics of the chosen Lean tool used in the company}

The main way to regulate the working times of individual assembly stands is to measure the cycle time of these stands. The cycle time is the time needed by the operator to perform all actions on the stand until their repetition. The cycle time is measured in real time and determined on the basis of selected samples. Usually, but not always, the cycle time is established on the basis of the lowest reproducible sample time for the implementation of specific actions on the stand.

In the plant, a matrix was developed that defines the method for measuring the cycle time. People are able to perform the measurement by this method. The matrix also determines the waste that can be identified with use of various measurement methods. The matrix divides measurements into four stages of advancement: QUICK, STANDARD, MAJOR, ADVANCED ANALYSIS.

The first and primary method of measurement is the timing that is most commonly performed cycle times measurement with use of the stopwatch. The timing method used to measure allows regulation of the cycle on the stand and thereby determines the productivity of the stand. If the measured stand is limited in the process (the bottleneck), the result of the measurement shows the productivity of the process. Timing is a normative term time determination based on realtime analysis.

Time measurements consist of describing the system work, with particular emphasis on technologies, methods and working conditions, and to record an amount of reference, the influencing features, tact time, the degree of efficiency and real-time specified in individual sections of the course. In figure 1 a measurement sheet used during the measurement is presented.

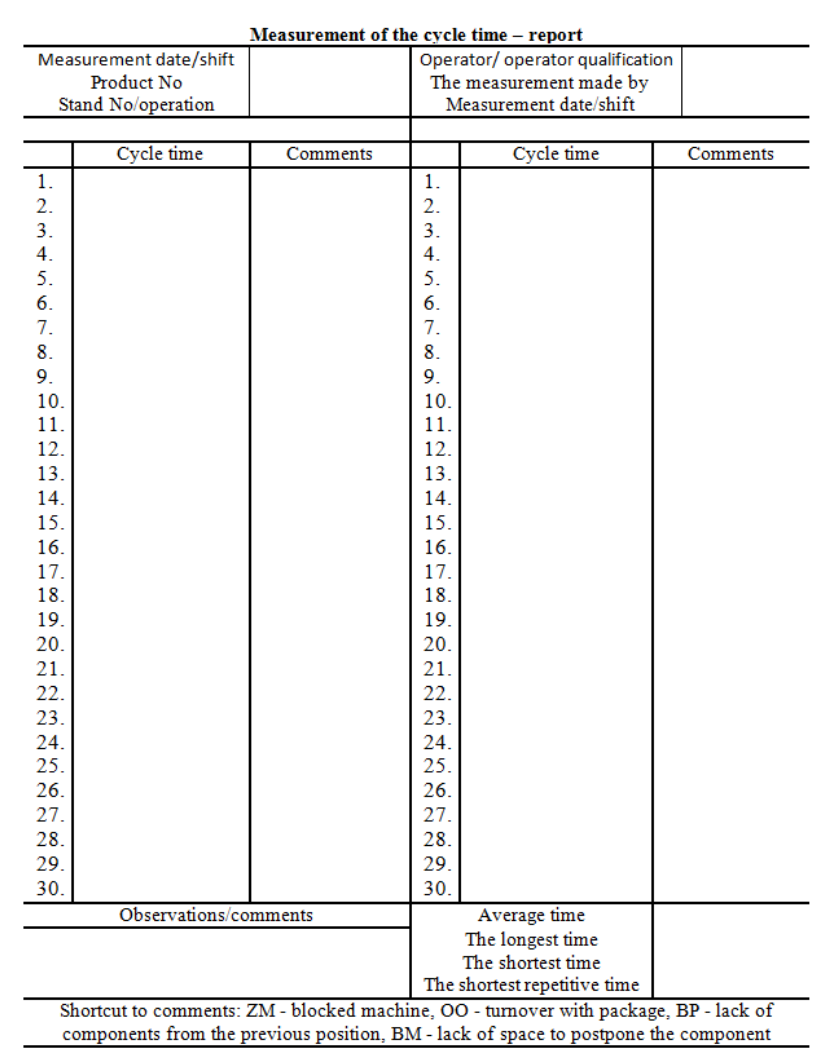

Fig. 1. Measurement sheet

Source: own study

The next method is a Yamazumi chart, which is a visual tool used within lean manufacturing to aid in cell design and continuous improvement; it allows visualization of the various work elements within a process and comparison to the required customer output or Takt time. The Yamazumi chart is a stacked bar chart that shows the balance of cycle time workloads between a number of operators typically in an assembly line or work cell. It can be either for a single product or multi product assembly line.

On the basis of previously conducted analyses, it is possible to visualize the amount of work on the production line, to balance workload and determine the added value, not added value and the insatiability of the process. The Yamazumi chart is often performed based on a video from a given stand. Analysing the video, it is possible to select a representative sample (defining actual cycle time of the stand), then divide the sample into individual motions that the operator performs on the stand by saving the actual duration of each of these movements. 
The example of the Yamazumi chart of seat belts plant is shown in figure 2.

Excel is the most suitable program for this particular chart. Using the cell as a unit of time (e.g. one cell is 0.5 seconds), it is possible to create a graph of the measured stand divided into individual movements of the operator. With the divided process, it is easy to determine the value added (VA), not value added (NVA) and the imbalance in the process. Furthermore, the so called imbalance or unsaturation (the name used by Fiat in WCM) - the "free" time on the stand after the end of the cycle (the difference between the cycle time of the stand and the „bottleneck”).

The Yamazumi chart is very useful to balance individual elements in the process. With proper movement of the elements (operations) in the process, it is possible to reduce unsaturation as much as possible in the process. Balancing is aimed at improving the efficiency of the process by reducing the number of operators or decrease the cycle time of the line. In figure 3 the balance in the process is presented.

After balancing (transfer of certain operations to other, less loaded stands) the number of operators for this process decreased and cycle time across the line decreased, which has an effect in higher efficiency of the process.

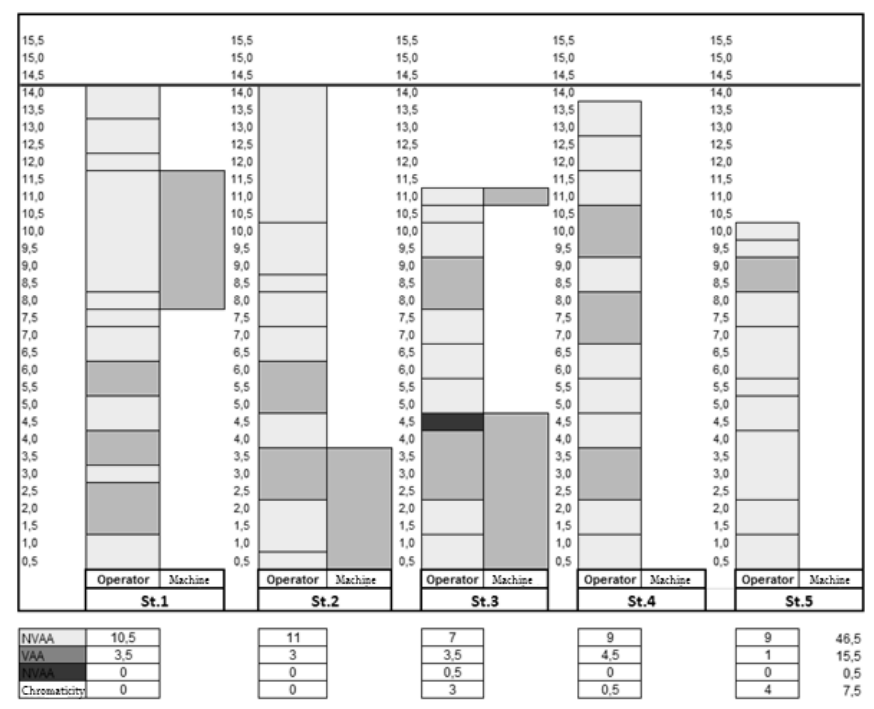

Fig. 2. Yamazumi chart a)

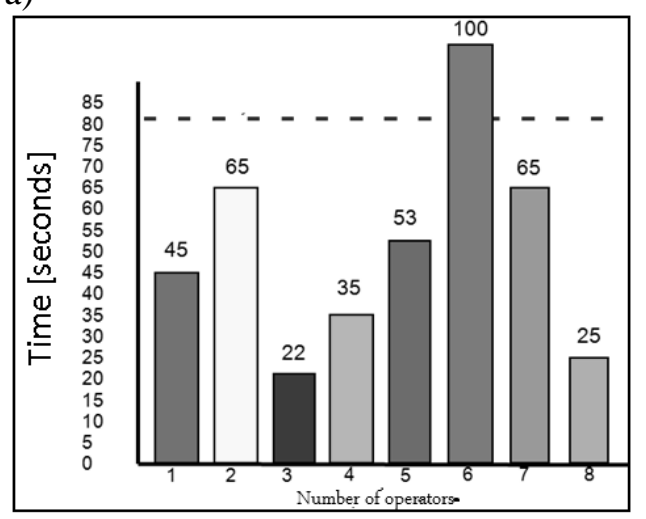

b)

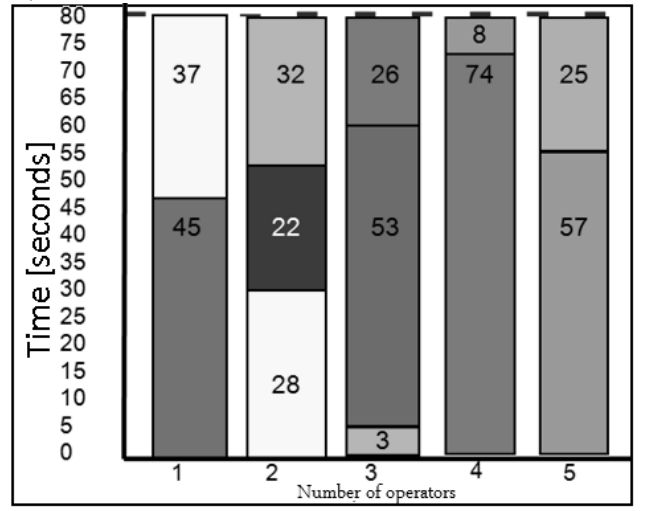

Fig. 3. Process graph: a) imbalanced, b) after balance Source: own study

The next method that is used in the measurements in the plant is the MTM method (CARAGNANO G., FISCHER H. 2010). It is a predetermined motion time system that is used primarily in industrial settings to analyze the methods used to perform any manual operation or task and, as a product of that analysis, set the standard time in which a worker should complete that task. This method consists of many kinds of methods such as: MTM1, MTM2, UAS, and MTM Logistics. The MTM is a measuring method, which is used to decompose movements in the course of elementary movements. To each extracted elements there is time value determined by features such as:

- control effort (volume control that is inserted to perform the activity, there are 3 types of the control efforts:

- low - control by the movement and the sense of touch, movement can be made without visual control

- medium - control by the movement and the sense of touch, at the end of the movement visual control 
- high - high coordination of muscles at the end of the movement, there may be mental control

- the length of movement

- case of movement (type of movement)

Elementary time systems are methods for the analysis of human workflow where the best example is the assembly. Their use leads to important clues for the development of the environment and working methods, and is used all over the world. Through detailed analysis of the working task MTM specifies the time, manner and quality of work, thus giving a complete picture of the implementation of the method together with insightful value-determining steps, visualize bottlenecks, and an indication of the direction of optimization. By making the planning analysis it is possible to accurately determine the potential of the area. Using MTM opportunities to develop along the entire value chain can be identified.

Standards, that arise as a result of analysis of MTM, are the result of the work of engineers who determine the optimal method of manufacturing, because MTM is used both in industrial, logistics, as well as repair shops and administration. The combination of MTM with value stream mapping results in an optimized operating system from the beginning of production, instead of the expensive process of gradual optimization.

MTM tools allow for identification of the best methods of implementation which allows for maximizing productivity by simplifying or eliminating elementary movements that do not generate added value. Time Management with use of MTM tools allows to create clear and unambiguous time standards at the highest level of quality.

Basic movements in the analysis MTM1 are natural human movements while performing activities in the workplace. Through analysis of the operator work, the cycle of his work is divided into the basic movements. In the MTM analysis the following movements are distinguished: reaching, grasping, relocation, connecting, releasing, control, walking, bending, crouch .

The individual movements are described in the relevant codes. These codes are standard throughout the world.

The MTM are methods that already allow during the design for optimization of the process, as well as regulate the times of the existing process. These processes can further optimize the various actions of the lean. Optimization of the production processes is not just about the operators. The research company is a typical assembly plant. Processes that are carried out in the company are manual and a manual-machine, so as to achieve the highest productivity of the process, the company should focus on optimizing the movement of machinery. For this purpose, a method of ARM (Machine Motion Analysis) is used. This method is based on the analysis of the various movements of the machine. To perform the optimization by ARM method a video that shows at least one full machine cycle is necessary. This video is analysed frame by frame and other individual movements of the machine are noted. Having analysed and written down the current state of movement of the machine, it is possible to save the actual time of these movements. Using video, any further movement of the machine in terms of its duration is analysed. Times of these movements (and possible movements of the operator) are saved and a table is created for this type of analysis. Then, after summing up the results, the cycle time of the stand is shown. After saving the time of the individual movements, the optimization of these movements can be done. Optimising the machine working time may help in balancing process or directly affect the productivity of the process when the optimized machine is "bottleneck" in the process. Sometimes, such analysis requires a financial outlay, such as hiring an external company needed to reprogram the machine.

\section{Literature}

1. Caragnano G., Fischer H. 2010: MTM - First Time Right. Polskie Stowarzyszenie MTM.

2. SYGUT P. 2013. Process of quality improvement in the company producing building materials. Production Engineering Archive, Vol. 1, No 1, p.16-18.

3. SZKLARZYK P. 2014. Visual inspection as one of the important elements of the quality control. Production Engineering Archive, Vol. 1, No 2, p.9-11.

4. WOMACK J.P., JONES D.T. 2001: Lean Thinkingszczupte myślenie. Wyd. ProdPublishing. Warszawa. 